Check for updates

Cite this: RSC Adv., 2018, 8, 18396

Received 6th February 2018

Accepted 11th April 2018

DOI: 10.1039/c8ra01150h

rsc.li/rsc-advances

\section{Synthesis and optical properties of lead-free cesium germanium halide perovskite quantum rodst}

\author{
Lin-Jer Chen (D)
}

Herein, the fabrication of a lead-free cesium germanium halide perovskite produced via a simple solvothermal process is reported for the first time. By tuning the composition of the $\mathrm{CsGeX}_{3}$ quantum rods, a power conversion efficiency of $4.92 \%$ under AM $1.5 \mathrm{G}$ was achieved.
The global need for renewable and "green" energy alternatives continues to spur on research in low-cost and high-efficiency photovoltaic devices. Completely inorganic $\mathrm{CsPbX}_{3}(\mathrm{X}=\mathrm{I}, \mathrm{Br}$, $\mathrm{Cl}$ ) perovskites constitute one kind of perovskite material and have been considered to be probable substitutes for organicinorganic perovskites. ${ }^{1,2}$ The hybrid, all-inorganic lead halide perovskites have generated enormous attention in the photovoltaic community due to their surprisingly rapid improvements in power conversion efficiency.,4 While recent investigations have been mostly focused on hybrid organicinorganic compounds, the study of their inorganic analogues, such as $\mathrm{ABX}_{3}(\mathrm{~A}=\mathrm{Rb}, \mathrm{Cs} ; \mathrm{B}=\mathrm{Ge}, \mathrm{Sn}, \mathrm{Pb} ; \mathrm{X}=\mathrm{Cl}, \mathrm{Br}, \mathrm{I})$, has been limited. ${ }^{5}$ However, the lead component is toxic and hence of high concern for human health, and can cause environmental damage, particularly because of its chemical stability. ${ }^{6,7}$ By replacing the lead component with germanium at the B-site, a lead-free perovskite can be formed, obviating the pollution problems and hence being environmentally friendly. Replacing unsafe lead in perovskites is essential in order to expand their applications. As a result, there has been a great deal of interest in replacing lead with nontoxic metals such as tin, bismuth, and germanium..$^{8-10}$

Over the past several years, considerable advances have been made toward the synthesis of colloidal semiconductor nanorods or nanofibers with diameters sufficiently small to produce a quantum confinement of charge carriers. Semiconductor quantum rods (QRs) show properties between zero-dimensional quantum dots (QDs) and one-dimensional quantum wires. ${ }^{11-13}$ Per unit mass, QR volumes are larger than QD volumes and therefore have significantly larger per-particle absorbance cross sections. ${ }^{14}$ This feature would be expected to increase the optical density of electrodes covered by up to a single layer of QR nanoparticles and therefore improve light harvesting. QRs are

Advanced Optoelectronic Technology Center, National Cheng Kung University, Tainan 70101, Taiwan.E-mail: linjerchen@gmail.com.

$\dagger$ Electronic supplementary information (ESI) available. See DOI: $10.1039 / \mathrm{c} 8 \mathrm{ra} 01150 \mathrm{~h}$ of great interest for fundamental research and are highly promising novel materials for new technologies. ${ }^{15,16}$ However, QR properties also depend on the quality of their internal crystal structure and may also exhibit decreased Auger recombination rates compared to those of quantum dots, ${ }^{17}$ which makes them potentially useful for advanced optoelectronic devices. Many modern methods have been developed for the synthesis of one-dimensional QRs. ${ }^{18,19}$ However, these preparation processes often require a relatively high temperature and vacuum, are complex, etc., while solvothermal methods offer great advantages such as low cost and flexibility. ${ }^{20-22}$ In this research we demonstrated a simple, rapid, and green solvothermal synthesis of high-quality lead-free perovskite-type $\mathrm{CsGeX}_{3}$ with a uniform QR-shaped structure, and found the use of this material to enhance photovoltaic efficiency. To our knowledge, this work is the first example of a solvothermal synthesis of high-quality $\mathrm{CsGeX}_{3}$ QRs with finely tunable PL and uniform diameters, and yielding high-performance solar cells showing efficiency levels up to $11 \%$.

As shown in Fig. 1, the optical absorbance and photoluminescence of all the tested inorganic perovskite quantum rods were red-shifted to longer wavelengths because of the confinement of the halide. ${ }^{23}$ The QR exhibited typically sharp absorption onsets, similar to those of the bulk dispersion. The slight shift of the first transition to longer wavelengths, when comparing $\mathrm{CsGeCl}_{3}$ to $\mathrm{CsGeI}_{3}$, might have been caused by a slight change in the lattice constant. Although a red shift in the absorption band was found for $\mathrm{CsGeX}_{3}$ (starting from $\mathrm{Cl}$ to $\mathrm{Br}$ to I), a $90 \mathrm{~nm}$ shift in the absorption onset (from 565 to 655 $\mathrm{nm}$ ) was observed when the halide ( $\mathrm{Cl}$ or $\mathrm{Br}$ or I) was used in the formation of $\mathrm{CsGeX}_{3}$ under similar conditions. Moreover, the overall intensity of the absorption band was altered. As such, the addition of different amounts of $\mathrm{Br}$ and I seemed to affect the optical properties of the perovskite composites. With the increased ratio of the amount of $\mathrm{Br}$ to the amount of I, the light absorption of the perovskite quantum rods in the visible-light range was gradually enhanced. This good agreement indicated 

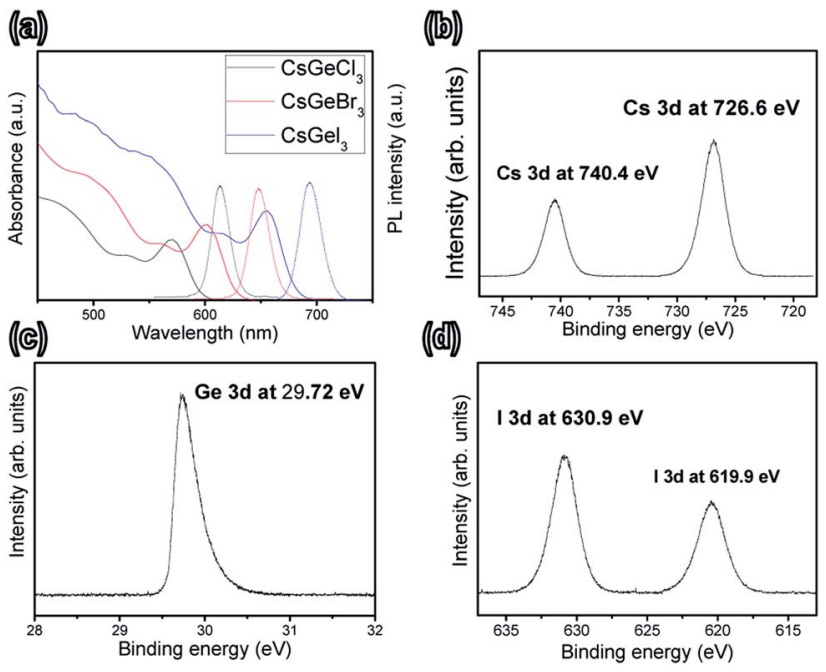

Fig. 1 (a) Optical absorption and photoluminescence spectra of $\mathrm{CsGeX}_{3}\left(\mathrm{X}=\mathrm{Cl}, \mathrm{Br}\right.$ and I). (b-d) XPS spectra of $\mathrm{CsGel}_{3}$ in the (b) Cs 3d, (c) Ge $3 d$ and (d) I 3d regions.

the halide improvement to be primarily resulting from the enhanced absorption due in turn to the lattice constant with larger atoms. When excited by light with a wavelength of 532 $\mathrm{nm}$, the wavelength of the photoluminescence emission from the QRs could be tuned from 607 to $696 \mathrm{~nm}$ with a full width at half-maximum (FWHM) of about $25 \mathrm{~nm}$.

The surface chemistry of $\mathrm{CsGeX}_{3}$ was investigated by X-ray photoemission spectroscopy (XPS) in Fig. 1b-d. Analysis of these spectra indicated the presence of Cs, Ge, and I, and hence demonstrated the high purity of the as-synthesized $\mathrm{CsGeI}_{3}$ quantum rods. Two distinct peaks appeared at $726.6\left(2 \mathrm{p}_{3 / 2}\right)$ and $740.4 \mathrm{eV}\left(2 \mathrm{p}_{1 / 2}\right)$, i.e., with a binding energy splitting of $13.8 \mathrm{eV}$. These observations were consistent the presence of $\mathrm{Cs}^{24} \mathrm{~A}$ peak was also observed at $29.72\left(3 d_{5 / 2}\right)$. This peak was attributed to Ge 3d, confirming the Ge state. ${ }^{25}$ In addition, peaks were observed at 619.9 and $630.9 \mathrm{eV}$. These peaks were attributed to I $3 \mathrm{~d}_{5 / 2}$, and were in good agreement with values reported for the oxidation state of halides. ${ }^{26}$ These results taken together demonstrated that $\mathrm{CsGeI}_{3}$ quantum rods were successfully synthesized. Fig. S1† shows the time-resolved PL decay curve of the $\mathrm{CsGeX}_{3}$ quantum rods. PL decay dynamics were recorded with $50 \mu \mathrm{W}$ of $3.0 \mathrm{eV}$ photons produced by a $35 \mathrm{fs}, 2 \mathrm{kHz}$ Ti:sapphire laser. The mean maximum-intensity lifetimes for samples $\mathrm{CsGeCl}_{3}, \mathrm{CsGeBr}_{3}$, and $\mathrm{CsGeI}_{3}$ were 16.8, 18.6, and 20.4 ns respectively, and corresponded to the previously reported radiative relaxation time of excitons associated with the hybrid perovskite nanocrystals. ${ }^{27}$ For the $\mathrm{CsGeI}_{3}$ quantum rods, the longest lifetimes were over $24.2 \mathrm{~ns}$, significantly longer than the lifetimes typically observed for other perovskite hybrid quantum rods. We suggest that this observation resulted from halide atom inhomogeneity (i.e., in atomic weight) and exciton radiative recombination in the small nanocrystals. ${ }^{28,29}$

Fig. 2a displays a transmission electron microscopy (TEM) image of the perovskite $\mathrm{CsGeI}_{3}$ quantum rods. Inspection of this image revealed the microscopic morphology and structural information of the composite, specifically that this perovskite

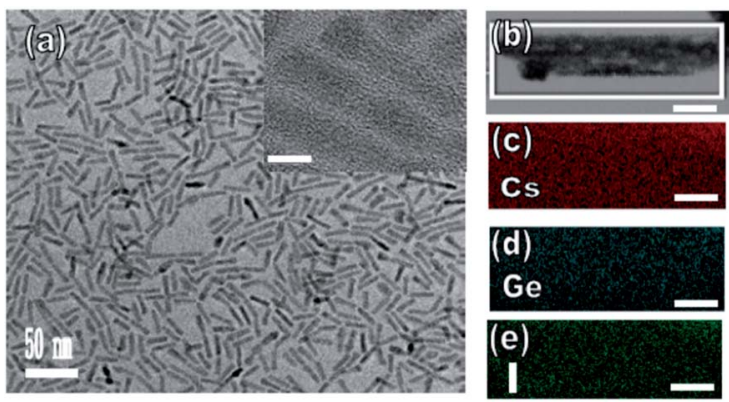

Fig. 2 (a) Typical high-resolution TEM image of the perovskite $\mathrm{CsGel}_{3}$ quantum rods. Inset shows a selected magnified TEM image of several QRs. (b) TEM image of the obtained perovskite quantum rods and (c-e) corresponding energy dispersive spectroscopy (EDS) elemental mapping images, specifically for (c) Cs, (d) Ge, and (e) I. These images confirmed that $\mathrm{Cs}, \mathrm{Ge}$, and I were sequentially and uniformly deposited onto the entire surface of each of the $\mathrm{CsGel}_{3}$ quantum rods on a copper grid. The scale bar is $5 \mathrm{~nm}$.

sample formed rod-like structures. Fig. 2a inset shows an HRTEM image of individual $\mathrm{CsGeI}_{3}$ quantum rods. Inspection of this image revealed a crystalline structure with observed lattice spacings of 0.58 and $0.56 \mathrm{~nm}$, corresponding, respectively, to the (110) and (200) planes of perovskite $\mathrm{CsGeI}_{3}$. In the PL spectra of all of the perovskite quantum rods, the PL emission bands were significantly enhanced compared to that of the $\mathrm{CsGeX}_{3}$ quantum rods, which demonstrated that increasing the atomic weight effectively passivated the defects on the surface of the $\mathrm{CsGeX}_{3} \cdot{ }^{30}$ Moreover, the PL intensity increased and red shifted with increasing atomic weight. As the atomic weight was increased from that of $\mathrm{Cl}$ to that of I, the intensity of the PL emission was observed to increase. Furthermore, the PL emission band for $\mathrm{CsGeI}_{3}$ was slightly red shifted relative to that for $\mathrm{CsGeCl}_{3}$, indicating that the size distribution of the $\mathrm{CsGeX}_{3}$ quantum rods increased during the solvothermal process. On the other hand, the $\mathrm{CsGeI}_{3}$ quantum rods showed very good crystallinity, a benefit for PL performance. However, compositional analysis of the quantum rods using XPS showed a molar $\mathrm{Cs} / \mathrm{Ge} / \mathrm{X}(\mathrm{X}=\mathrm{Cl}, \mathrm{Br}$, and $\mathrm{I})$ ratio of $1: 1: 3$. Analysis of individual particles using EDS also showed a ratio of $1: 1: 3$, with a variation from particle to particle of less than the approximately \pm 2 atom\% experimental error (see Table S1†). Accordingly, the continuity of the fiber suggested the high quality of our $\mathrm{CsGeX}_{3}$ quantum rods. Moreover, measurements taken from 150 quantum rods in our sample revealed them to have an average diameter of about $5 \mathrm{~nm}$, with a deviation of about 15-18\%, which indicated the high quality of our samples. Additionally, the typical rods had lengths of several tens of nanometers. Fig. 2b-e show Cs, Ge, and I elemental mappings of the $\mathrm{CsGeI}_{3}$ quantum rods obtained via TEM energy-dispersive X-ray spectroscopy (EDS). Analysis of these images indicated the formation of ternary perovskite $\mathrm{CsGeI}_{3}$ quantum rods consisting of Cs (red), Ge (blue), and I (green) distributed throughout the quantum rod. The quantitative EDS analysis of a $\mathrm{CsGeI}_{3}$ quantum rod indicated a Cs: Ge : I atomic ratio of about $0.96: 0.94: 2.85$, quite close to the nominal $1: 1: 3$ ratio given by stoichiometry of the precursor solutions. This result clearly 
showed the quantum rod to be mainly composed of $\mathrm{CsGeI}_{3}$. Similar quantitative results were also obtained from EDS measurements (SEM) and X-ray photoelectron spectroscopy (XPS) analysis (Table S1 $\dagger$ ). Further experiments were also performed to estimate the film stability under various conditions (Fig. S2 $\dagger$ ). We took absorbance measurements of the $\mathrm{CsGeI}_{3}$ and $\mathrm{CH}_{3} \mathrm{NH}_{3} \mathrm{PbI}_{3}$ perovskite films under the same conditions. When $\mathrm{CH}_{3} \mathrm{NH}_{3} \mathrm{PbI}_{3}$ films were exposed to air for a period of time, the intensity of the absorption edge rapidly decreased after $2 \mathrm{~h}$, and the edge completely disappeared after $15 \mathrm{~h}$ (Fig. S2: $\uparrow$ black), indicating the decomposition of the perovskite structure. The color of the film also correspondingly changed from dark red to light brown within $3 \mathrm{~h}$ (inset of Fig. S2 $\dagger$ ), which implied the disintegration of the perovskite structure. Our simple strategy can be extended to other perovskite systems for improving their stability. Under the same conditions, the $\mathrm{CsGeI}_{3}$ perovskite film showed a slow decomposition (i.e., an approximately 45\% decomposition in $48 \mathrm{~h}$ ), whereas the $\mathrm{CH}_{3} \mathrm{NH}_{3} \mathrm{PbI}_{3}$ film showed a rapid degradation (i.e., 98\% decomposition in less than $24 \mathrm{~h}$ ).

Fig. 3a shows typical current density-voltage $(J-V)$ curves for completely inorganic lead-free perovskite solar cells with the different halides $(\mathrm{Cl}, \mathrm{Br}$, or $\mathrm{I})$, and the curves were obtained in the presence of different concentrations of halide under air mass (AM) 1.5 G solar irradiation; the photovoltaic parameters are summarized in Table $\mathrm{S} 2 . \dagger$ The best solar cell performance was measured when using the $\mathrm{CsGeI}_{3}$ quantum rod perovskite, and showed a short-circuit current density $\left(J_{\mathrm{sc}}\right)$ of $18.78 \mathrm{~mA}$ $\mathrm{cm}^{-2}$, open-circuit voltage $\left(V_{\mathrm{oc}}\right)$ of $0.51 \mathrm{~V}$, fill factor $(\mathrm{FF})$ of 0.51 , and the power conversion efficiency (PCE) of $4.94 \%$. The best solar cell using the $\mathrm{CsGeBr}_{3}$ quantum rod perovskite showed a $J_{\mathrm{sc}}$ of $19.49 \mathrm{~mA} \mathrm{~cm}{ }^{-2}, V_{\mathrm{oc}}$ of $0.48 \mathrm{~V}, \mathrm{FF}$ of 0.52 , and PCE of $4.92 \%$. And the best solar cell using $\mathrm{CsGeCl}_{3}$ quantum rods showed a $J_{\mathrm{sc}}$ of $18.57 \mathrm{~mA} \mathrm{~cm}^{-2}, V_{\mathrm{oc}}$ of $0.35 \mathrm{~V}$, FF of 0.40 , and PCE of $2.57 \%$. That is, the solar cell PCE was lowest when its perovskite included the halide with the lowest atomic volume, i.e., Cl. This decrease was primarily the result of the reduced $J_{\mathrm{sc}}$, $V_{\text {oc }}$, and FF. The IV and PCE values of the $\mathrm{CsGeI}_{3}$ and $\mathrm{CsGeBr}_{3}$ were better than the values measured for $\mathrm{CsGeCl}_{3}$, demonstrating the benefits of $\mathrm{CsGeI}_{3}$ as an absorber material. Note that a Cs: : Ge : I molar ratio of $1: 0.92: 2.52$ molar ratio in the device was found to be optimum for device performance (see Table S2, ESI $\dagger$ ). A group of devices, with five devices for each composition tested, was fabricated in order to further explain the relationship between device performance and halide ratio. Performance statistics for the lead-free perovskite quantum rod solar cells are provided in Fig. S3 of the ESI; $\uparrow$ these cells showed excellent reproducibility with an average efficiency of $3.57 \% \pm$ $0.5 \%$. From these studies, we concluded that including the indicated amount of I precursor improved all of the photovoltaic parameters. In addition, perovskite crystallinity has been shown to influence the ultimate performance of the constructed device, with this influence attributed to defects in the crystals forming shorting and trapping sites for charge recombination. Crystallinity has also been shown to very much influence charge transport, separation, and diffusion length. ${ }^{31,32}$ Solar cells with high FF values have been shown to display active charge transfer and extraction from their planar $\mathrm{p}-\mathrm{i}-\mathrm{n}$

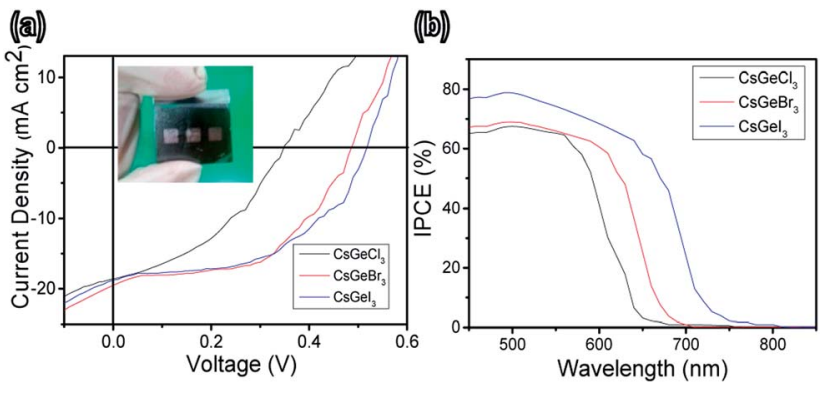

Fig. 3 (a) $J-V$ characteristics of $\mathrm{CsGel}_{3}$ (blue), $\mathrm{CsGeBr}_{3}$ and $\mathrm{CsGeCl}_{3}$ (red, and black) solar cells. The inset shows a photograph of the flexible device. (b) IPCE of $\mathrm{CsGeX}_{3}$ perovskite devices with different halide ratios. The photovoltaic results are summarized in Table $\$ 2 . \dagger$

heterojunctions. ${ }^{33}$ The resulted in the greater efficiency of the device formed on quantum rods, which motivated us to explore the influence of our solvothermal method on this facile system. The external quantum efficiency (EQE) plotted in Fig. 3b confirms the increased $J_{\text {sc }}$ values of these devices, in which the merged $J_{\mathrm{sc}}$ values for the devices derived from lead-free perovskites $\mathrm{CsGeI}_{3}, \mathrm{CsGeBr}_{3}$ and $\mathrm{CsGeCl}_{3}$ were determined to be $11.08,10.22$, and $9.15 \%$, respectively. The maximum EQE values of the top-performing devices were observed to exceed $66 \%$ (for $\mathrm{CsGeCl}_{3}$ ), 68\% (for $\mathrm{CsGeBr}_{3}$ ) and $79 \%$ (for $\mathrm{CsGeI}_{3}$ ). We plan to investigate the use of the completely inorganic lead-free quantum rods as absorber materials in perovskite solar cells; we plan to do so since these rods may improve the cell characteristics due to their low cost, low toxicity, high chemical and photo-stabilities, and good thermal effects, compared to organic composites. ${ }^{34}$ The is expected to increase the optical density of active layer and therefore improve light harvesting. Furthermore, the surface areas of quantum rods are greater than those of the bulk material, which may allow for greater contact areas and hence improve the conversion efficiency. The resulted can further improve charge separation efficiency, leading to higher performance of the perovskite solar cells.

\section{Conclusions}

$\mathrm{CsGeX}_{3}(\mathrm{X}=\mathrm{Cl}, \mathrm{Br}$, and $\mathrm{I})$ with tunable emission wavelengths ranging from 607 to $696 \mathrm{~nm}$ have been prepared through a versatile and relatively inexpensive technique involving the use of composite quantum rods under different halide salt conditions. In this work, we found that the optical properties of the completely inorganic lead-free perovskites can be altered without annealing by using a solvothermal process, which makes them attractive for novel optoelectronic devices. Highquality lead-free perovskite quantum rods with compositiontunable emission have been synthesized using a simple solvothermal synthetic approach. Emission wavelengths spanning the visible spectrum could be facilely tuned by altering the composition of the halide salts. Finally, a remarkable enhancement in the photovoltaic performance of the $\mathrm{CsGeX}_{3}$ devices, specifically with power conversion efficiency values close to $4.94 \%$, was realized. We fully expect this work to contribute to a fundamental understanding of the structural, 
morphological and optical properties of lead-free halide perovskite quantum rods. We also expect these rods to be useful for inexpensive nontoxic optical materials, light absorbers for solar cells, or other electric devices, LEDs, and biosensor materials.

\section{Conflicts of interest}

There are no conflicts to declare.

\section{Acknowledgements}

The authors thank the Ministry of Science and Technology, Taiwan (MOST) and National Cheng Kung University for supporting this research.

\section{Notes and references}

1 G. Zhang, G. Liu, L. Wang and J. T. S. Irvine, Chem. Soc. Rev., 2016, 45, 5951.

2 Y. Zhao and K. Zhu, Chem. Soc. Rev., 2016, 45, 655.

3 Y. Zhang, J. Liu, Z. Wang, Y. Xue, Q. Ou, L. Polavarapu, J. Zheng, X. Qi and Q. Bao, Chem. Commun., 2016, 52, 13637.

4 L. K. Ono, M. R. Leyden, S. Wang and Y. Qi, J. Mater. Chem. A, 2016, 4, 6693-6713.

5 L. Zuo, Z. Gu, T. Ye, W. Fu, G. Wu, H. Li and H. Chen, J. Am. Chem. Soc., 2015, 137, 2674.

6 M. Grätzel, Nat. Mater., 2014, 13, 838.

7 M. Konstantakou and T. Stergiopoulos, J. Mater. Chem. A, 2017, 5, 11518-11549.

8 F. Hao, C. C. Stoumpos, D. H. Cao, R. P. H. Chang and M. G. Kanatzidis, Nat. Photonics, 2014, 8, 489.

9 J. Chen, S. Zhou, S. Jin, H. Li and T. Zhai, J. Mater. Chem. C, 2016, 4, 11.

10 Q. Shen, Y. Ogomi, J. Chang, T. Toyoda, K. Fujiwara, K. Yoshino, K. Sato, K. Yamazaki, M. Akimoto, Y. Kuga, K. Katayama and S. Hayase, J. Mater. Chem. A, 2015, 3, 9308-9316.

11 M. V. Mukhina, V. G. Maslov, A. V. Baranov, A. V. Fedorov, A. O. Orlova, F. Purcell-Milton, J. Govan and Y. K. Gun'ko, Nano Lett., 2015, 15, 2844.

12 M. V. Mukhina, V. G. Maslov, A. V. Baranov, A. V. Fedorov and K. Berwick, RSC Adv., 2013, 3, 20746-20749.

13 A. Kostopoulou, M. Sygletou, K. Brintakis, A. Lappasa and E. Stratakis, Nanoscale, 2017, 9, 18202.

14 L. X. Hung, P. D. Bassène, P. N. Thang, N. T. Loan, W. D. Marcillac, A. R. Dhawan, F. Feng, J. U. Esparza-Villa, N. T. T. Hien, N. Q. Liem, L. Coolen and P. T. Nga, RSC Adv., 2017, 7, 47966.
15 C. Hamon, A. Ciaccafava, P. Infossi, R. Puppo, P. EvenHernandez, E. Lojou and V. Marchi, Chem. Commun., 2014, 50, 4989.

16 M. R. Golobostanfard and H. Abdizadeh, J. Power Sources, 2014, 256, 102.

17 M. Kazes, D. Y. Lewis, Y. Ebenstein, T. Mokari and U. Banin, Adv. Mater., 2002, 14, 317.

18 M. Kazes, D. Oron, I. Shweky and U. Banin, J. Phys. Chem. C, 2007, 111, 7898.

19 G. Jia and U. Banin, J. Am. Chem. Soc., 2014, 136, 11121.

20 M. Fathy, H. Hamad and A. E. H. Kashyout, RSC Adv., 2016, 6, 7310 .

21 L. J. Chen, C. R. Lee, Y. J. Chuang, Z. H. Wu and C. Chen, J. Phys. Chem. Lett., 2016, 7, 5028.

22 A. Spepi, C. Duce, C. Ferrari, J. González-Rivera, Z. Jagličić, V. Domenici, F. Pineider and M. R. Tine, RSC Adv., 2016, 6, 104366.

23 N. K. Kumawat, A. Dey, A. Kumar, S. P. Gopinathan, K. L. Narasimhan and D. Kabra, ACS Appl. Mater. Interfaces, 2015, 7, 13119.

24 T. Gao, P. Norby, H. Okamoto and H. Fjellvag, Inorg. Chem., 2009, 48, 9409.

25 S. Gupta, R. Chen, Y. C. Huang, Y. Kim, E. Sanchez, J. S. Harris and K. C. Saraswat, Nano Lett., 2013, 13, 3783.

26 K. Shimizu, A. Shchukarev, P. A. Kozin and J. F. Boily, Langmuir, 2013, 29, 2623.

27 M. I. Dar, M. Abdi-Jalebi, N. Arora, T. Moehl, M. Grätzel and M. K. Nazeeruddin, Adv. Mater., 2015, 27, 7221.

28 N. Yantara, S. Bhaumik, F. Yan, D. Sabba, H. A. Dewi, N. Mathews, P. P. Boix, H. V. Demir and S. Mhaisalkar, J. Phys. Chem. Lett., 2015, 6, 4360.

29 C. C. Stoumpos, C. D. Malliakas, J. A. Peters, Z. F. Liu, M. Sebastian, J. Im, T. C. Chasapis, A. C. Wibowo, D. Y. Chung and A. J. Freeman, Cryst. Growth Des., 2013, 13, 2722.

30 A. Wood, M. Giersig, M. Hilgendorff, A. V. Campos, L. M. Lizmarzan and P. Mulvaney, Aust. J. Chem., 2003, 56, 1051.

31 G. Xing, N. Mathews, S. Sun, S. S. Lim, Y. M. Lam, M. Gratzel, S. Mhaisalkar and T. C. Sum, Science, 2013, 342, 344.

32 P. Docampo, J. M. Ball, M. Darwich, G. E. Eperon and H. J. Sniath, Nat. Commun., 2013, 4, 2761.

33 S. Sun, T. Salim, N. Mathews, M. Duchamp, C. Boothroyd, G. Xing, T. C. Sum and Y. M. Lam, Energy Environ. Sci., 2014, 7, 399.

34 T. Erdem and H. V. Demir, Nat. Photonics, 2011, 5, 126. 